\title{
Un acercamiento multidisciplinar a las dimensiones del desarrollo humano
}

\author{
Jesús Alfredo Morales Carrero \\ Magister en Orientación Educativa \\ Politólogo y Docente de Psicología y Orientación \\ Universidad de Los Andes, Venezuela \\ lectoescrituraula@gmail.com \\ ORCID: https://orcid.org/0000-0001-8533-3442
}

Recepción: 14-09-2020 / Aceptación: 22-11-2020

\section{Resumen}

El presente artículo plantea un acercamiento a las dimensiones del desarrollo humano desde una mirada multidisciplinar, que precisa la necesidad de atenderle global, holística y sistémicamente para que alcance la realización individual y social.

La disertación obedece a una revisión documental en la que se precisan las aportaciones de teóricas, conceptuales y epistemológicas, que sustentan el desarrollo humano como propósito de los programas educativos y políticos. Desde este enfoque, se concluye que el ser humano, como sistema supra-complejo, requiere la integración de esfuerzos estratégicos y de políticas inclusivas, que impulsen el desarrollo multifacético y multidimensional que potencien su crecimiento, bienestar integral y calidad de vida.

Palabras clave: Educación, desarrollo humano, dimensiones, bienestar integral, calidad de vida, políticas.

\begin{abstract}
This article proposes an approach to the dimensions of human development from a multidisciplinary perspective, which specifies the need to address it globally, holistically and systemically so that it achieves individual and social fulfillment.

The dissertation is due to a documentary review in which the theoretical, conceptual and epistemological contributions that support human development as the purpose of educational and political programs are specified. From this approach, it is concluded that the human being, as a supra-complex system, requires the integration of strategic efforts and inclusive policies that promote multifaceted and multidimensional development that enhance growth, comprehensive well-being and quality of life.
\end{abstract}

Key words: Education, human development, dimensions, integral wellness, quality of life, polícies. 


\section{Introducción}

El desarrollo de la humanidad ha representado históricamente una preocupación de la mayor parte de los sistemas educativos y políticos del mundo. Por ende, las políticas sociales y los esfuerzos institucionales se han enfocado en fortalecer el desenvolvimiento de las potencialidades del individuo, con el propósito de garantizar su autorrealización, el alcance pleno de sus virtudes y la consolidación de sus libertades (Morales, 2020c; Pérez, 2005; Sabino, 2004; Sen, 2000).

Desde un enfoque amplio, el desarrollo humano se entiende como la creación de las condiciones sociales, económicas, culturales, afectivas y morales, que permitan el impulso de las competencias y destrezas necesarias para generar bienestar individual y colectivo. Sandoval (2012), refiriéndose a la perspectiva humanista, plantea que el ser humano implica "el desarrollo positivo y saludable, a través del ejercicio de las capacidades distintivamente humanas de la escogencia, creatividad y la autorrealización" (p.54). Esto implica la satisfacción de necesidades básicas y superiores que coadyuven con la realización plena (Maslow, 1954); por su parte, la perspectiva sociocultural enfatiza en la necesidad de promover -desde edades tempranas- el desarrollo de las funciones psíquicas superiores como procesos vinculados con la interacción y la mediación con el medio.

Para Griffin (2001), se trata de propiciar "la ampliación de las capacidades de las personas para que dispongan de una gama de opciones, que le posibiliten hacer más cosas; vivir una vida más larga, eludir enfermedades evitables y tener acceso a la reserva mundial de conocimiento" (p.13). Este enfoque posiciona al desarrollo humano como ideal socioeducativo y político, que procura el fortalecimiento de las competencias y la potenciación de las capacidades colectivas, como estrategia para mejorar la calidad de vida; mediante la erradicación de las limitantes históricas (pobreza, desigualdad, exclusión).

En tal sentido, la búsqueda de equilibrio en la satisfacción de las necesidades del ser humano, refiere a varios aspectos: bienestar integral (personal y económico); acceso a la educación de calidad, capacidad para optar por los requerimientos de atención médica (preventiva), que garantice una vida óptima, goce de las libertades y el incremento progresivo de las posibilidades para realizarse socio-afectiva $y$ emocionalmente. Desde la mirada de las políticas públicas, este desarrollo involucra ampliar las condiciones para que el individuo mejore sus capacidades en todas sus dimensiones: esperanza de vida, grado de alfabetización, acceso a los bienes y servicios de calidad; así como la inclusión a lo largo del tiempo (Carballeda, 2012; Elizalde, 2012).

Atender estos cometidos, históricamente ha representado un elevado desafío para las políticas públicas como acciones estratégicas de intervención multidimensional y transversal del Estado; entre otras razones, por la complejidad de las exigencias sociales y la diversidad que caracteriza a necesidades colectivas, a las que se han abordado parcialmente y no desde esfuerzos inter y multidisciplinares. Tanto 
esta condición, como el escaso sentido de coresponsabilidad ciudadana han impulsado la improvisación y la ejecución de propuestas homogéneas, cuya limitada correspondencia con las particularidades sociales y las necesidades coyunturales reales, han hecho inevitable la prolongación de los padecimientos colectivos, entre los que se precisan: la pobreza, la exclusión y discriminación; el deterioro progresivo y sistemático de la calidad de vida; el incremento de situaciones conflictivas asociadas con la delincuencia; el consumo de sustancias y la desintegración familiar. Todos estos factores articulados obstaculizan el desarrollo integral y la dignificación del ser humano.

Para Sen (2000), el desarrollo humano tiene como objetivo fundamental, lograr que el individuo ejercite sus libertades individuales y sociales, como facultades que garanticen su integración en las actividades productivas, la realización de iniciativas vinculadas con la innovación y el emprendimiento; así como su inserción en la vida económica. Todos estos elementos se entienden necesarios para la consolidación de una vida plena y satisfactoria. Por su parte Sarramona (2002) manifiesta que alcanzar niveles importantes de estabilidad en todas las dimensiones humanas, requiere potenciar su bagaje de competencias, habilidades y destrezas; lo que implica a la educación como el proceso para impulsar las áreas "sensoriales, mentales, motrices, actitudinales, su inteligencia y aprendizaje" (p.85).

Para la psicología educativa se trata de motivar las capacidades mentales en sintonía con el desarrollo social, afectivo y emocional, que le permitan al individuo lograr niveles óptimos de equilibrio (Gutiérrez, 2005). Esto significa canalizar aptitudes y atender intereses diversos que refieren a la complejidad como se presen$\tan$ las necesidades humanas, a sus particularidades y los modos desde los que pueden ser abordadas para garantizar la realización personal y social del ser humano. Para Camps (2000), desde un enfoque filosófico, potenciar el bienestar humano demanda acciones educativas que le permitan al individuo integrarse socialmente, con la disposición para afrontar, desde los valores éticos y morales, los obstáculos que definen su convivencia y el alcance de su autorrealización.

Sarramona (2002), refiriéndose a la convivencia humana como determinante del desarrollo humano integral, plantea que se trata de fortalecer el compromiso social, el respeto y el reconocimiento del otro; en función de la integración de un cúmulo de valores que garanticen el bien común, a decir "libertad, honradez, colaboración, solidaridad, responsabilidad, capacidad de sacrificio, aceptación de la norma emanada de la autoridad legal" (p.91).

En esta misma dirección, la educación para la ciudadanía mundial propone que, hoy más que nunca, el rol de la formación con pertinencia social toma especial importancia, pues sus implicaciones son vistas como garantes de fomentar conductas morales, que mediadas por el diálogo reflexivo y activo den lugar a la tolerancia, al respeto pleno y a la superación de los conflictos sociales (Unesco, 2015). 
En atención a estas necesidades individuales y sociales, se propone una revisión de las dimensiones del desarrollo humano; precisando desde el punto de vista integral, multifacético y holístico el bienestar y la calidad de vida.

\section{Desarrollo}

\section{a. Dimensiones del desarrollo humano}

La búsqueda de mejoras significativas en la calidad de vida y el bienestar integral se han consolidado como dimensiones que, por sus implicaciones y aportaciones, determinan el desarrollo humano integral; la dignificación de la convivencia y la ampliación de las oportunidades para que el individuo logre maximizar las posibilidades de autorrealización personal (Morales, 2020a). Esta postura, para la psicología humanista, refiere a la búsqueda sistemática de crecimiento multidimensional que favorezca el cumplimiento de los intereses y preferencias, el cumplimiento de las metas y la elevación de la condición humana, como cometidos necesarios de los que depende el logro de las más sublimes aspiraciones (Rogers, 1989).

Por ende, las políticas públicas como acciones de transformación multidimensional han considerado la necesidad de crear las condiciones apropiadas en las que el ser humano logre desarrollar su potencial, mediante la aplicación de programas integrales y holísticos que, con apoyo de la interdisciplinariedad motiven estilos de vida, que cooperen con la realización plena de sus competencias, destrezas y habilidades. Esto supone fomentar el desarrollo personal y la inclusión social en igualdad de condiciones, en un intento por lograr que el individuo asuma - desde el sentido de co-responsabilidad - su rol como transformador de sí mismo y de su propia realidad. En otras palabras, se trata de consolidar el desarrollo pleno y el alcance del potencial completo, como requerimientos para lograr la autorrealización $y$ el funcionamiento competitivo en las dimensiones: social, psicológica, socio-afectiva, emocional, biológica y espiritual.

Según expone Jiménez (2010), la realización de este cúmulo de dimensiones requiere la unificación no solo de voluntades políticas, sino disciplinares como el proceso estratégico necesario para garantizar la sostenibilidad de las acciones individuales y colectivas. Estas dependen, en modo significativo, de la satisfacción de las necesidades mediante "el equilibrio de esfuerzos encaminados a mejorar la calidad de vida con la solidaridad intra-e intergeneracional, sin limitar las potencialidades futuras de supervivencia”. (p.14)

Lo anterior supone, entre otras cosas, la articulación de esfuerzos en torno a la búsqueda de mayores oportunidades de calidad de vida, como el proceso dinámico, abierto e inclusivo que procura fortalecer el desarrollo personal y colectivo del individuo; mediante la "ampliación de las posibilidades para disfrutar de una vida prolongada y saludable, adquirir conocimientos y tener acceso a los recursos necesarios para lograr un nivel de vida decente" (Jiménez, 2010, p.6). Frente a este complejo desafío, la tarea de las acciones políticas de 
intervención estratégica requieren la integración de saberes disciplinares, en función de los cuales enriquecer las miradas teóricas y metodológicas que redunden en la generación de procesos de transformación creativos, productivos y efectivos, que progresivamente incorporen nuevas alternativas vinculadas con la calidad de vida y el bienestar integral.

Al respecto, Cloninger (2003) indica que el trabajo inter-y multidisciplinar constituye una alternativa de apertura a la exploración, definición y abordaje de la exclusión y la desigualdad social; generando de este manera, procesos de transformación integral que garanticen "el crecimiento óptimo y el desarrollo del potencial humano, minimizando los obstáculos de la autorrealización y, en su lugar, diversificar las alternativas que alienten el despliegue de las cualidades humanas necesarias para lograr el cambio social" (p.460). Parafraseando a Lafarga (2016), esta búsqueda de bienestar multidimensional requiere la integración de elementos metodológicos derivados de aportaciones interdisciplinares, que cooperen con la construcción de sistemas de transformación, que no solo coadyuven con la comprensión de las complejas necesidades sociales e individuales, sino como la generación de nuevas posibilidades que liberen el potencial humano.

Para Sabino (2004), atender la supra-complejidad humana - además de responsabilidad de las políticas educativas y sociales - exige el diseño de acciones de intervención holísticas y globales, con la capacidad de atender las necesidades básicas de fortalecer el desarrollo multifacético, y el acceso a los bienes y servicios; así como a las condiciones fundamentales para potenciar las posibilidades para que el ser humano alcance niveles de plenitud y realización social. De allí que el autor afirma que, "los cometidos del Estado deben enfocar sus esfuerzos en garantizar la competitividad del individuo para enfrentar los desafíos de una sociedad sometida al cambio y a la transformación recurrente" (p.6).

En tal sentido, este apartado procura una aproximación integral a los requerimientos que se erigen en el presente siglo para lograr el desarrollo humano, precisando la necesidad de generar procesos de intervención con especial énfasis en la atención a la supra-complejidad del individuo, a quien se le debe garantizar, entre otras cosas, el cumplimiento de sus libertades individuales y colectivas, pero además, el acceso a una educación con enfoque global, a la participación en los asuntos públicos, a la consolidación de actividades, preferencias e intereses profesionales y a la capitalización de sus competencias y habilidades, en función de las cuales actuar con autonomía, conciencia y sentido de co-responsabilidad en la transformación de sus propias condiciones de vida y en las de sus pares. Estas dimensiones se precisan a continuación:

\section{b. Dimensión afectiva y socio-emocional}

Las implicaciones derivadas de un sistema social sometido al cambio recurrente han generado el deterioro de las relaciones entre los actores del núcleo familiar; así como déficit en 
los procesos comunicativos y el acercamiento emocional necesario para definir una identidad sólida y configurar la personalidad. En razón de este panorama, el rol de los factores de socialización y, en especial el de la familia y escuela, toman singular importancia por ser los responsables de educar en "la autoestima, en competencias sociales y afectivas, así como para la felicidad" (Bisquerra, 2011, p.16).

Desde la perspectiva de Nardone, Giannotti y Rocchi (2003), el equilibrio emocional como proceso inherente a la familia exige "relaciones más orientadas al diálogo, favorables a una mejor comunicación y con mayor aproximación tutelar y educativa" (p.27). Lo anterior indica que la participación de otros (padres y docentes) contribuye con el proceso de desarrollo socioemocional, indispensable para consolidar conductas independientes y comportamientos autónomos para funcionar en el contexto social, en el establecimiento de relaciones con sus pares; así como en la integración competitiva y afectiva a la sociedad.

Maturana (1990) aporta a esta posición que la vida humana tiene sus fundamentos en lo emocional y en lo social. Por esta razón, el afecto contribuido por los miembros del núcleo familiar garantiza sensaciones positivas de seguridad y confianza, las cuales - a su vez - definen la aceptación, la convivencia sana, conductas respetuosas y cónsonas con el autorrespeto y el reconocimiento del otro.

Para Nardone, Giannotti y Rocchi (2003), la formación afectiva incumbe especialmente a la familia, sin que ello implique la exclusión de los demás factores de socialización. Sin embargo, es la familia a la que corresponde ofrecer "protección y motivar el desarrollo de responsabilidades en los que respecta a la formulación de proyectos personales" (p.16). Esto significa, promover la autoconfianza, la autonomía y las competencias emocionales para resolver situaciones concretas que les permitan funcionar, tanto individual como socialmente con independencia y confianza en sí mismo.

Para la psicología humanista, potenciar la dimensión socio-afectiva y emocional sugiere generar un clima psicológico positivo a nivel familiar, en el que prime el crecimiento individual, se promueva la libertad, la felicidad y los vínculos que definen el respeto por las particularidades individuales. Este ambiente de solidaridad y empatía debe entenderse como un aspecto medular que coopera con la ampliación de la personalidad, la emergencia de la creatividad y de la seguridad en las capacidades propias (Maslow, 2008; Rogers, 1989). Al respecto, Aristizábal (2015) deja ver que el desarrollo pleno del ser humano demanda de acciones de atención integral, destinadas a fortalecer tanto a nivel familiar como social, la consolidación de competencias afectivas en las dimensiones "interpersonal, íntima, existencial y personal; en función de las cuales, posibilitar que el individuo funcione socialmente y desarrolle vínculos que motiven la construcción de redes de apoyo y de cooperación” (p.258).

En palabras de Corkille (1970), el ingrediente fundamental que debe procurar cualquier 
política de intervención socioeducativa, para garantizar el bienestar integral y la calidad de vida, consiste en el establecimiento de nexos sólidos, que dimensionen y le otorguen sentido a la vida. Esto debe entenderse como la recuperación y el tratamiento de la familia como el núcleo social elemental, del cual depende la adopción de actitudes vinculadas con "la confianza interna, el sentimiento de tener objetos y compromisos; relaciones significativas y constructivas con los demás, mediante la elevación de la autoestima como regla básica para maximizar la posibilidad para triunfar" (p.12).

Se trata entonces, de crear las condiciones psicológicas, emocionales y socio-afectivas que garanticen el funcionamiento pleno, el despliegue de las bondades propias de la creatividad y la estabilidad integral, como aspectos derivados de la satisfacción de necesidades de atención y el tratamiento afectivo positivo; a los cuales se consideran cimientos del bienestar emocional, del que a su vez depende el logro de una vida digna, gratificante y saludable. Esto sugiere garantizar el crecimiento óptimo del ser humano mediante la promoción de nexos sólidos, provenientes de diversas direcciones (familia, escuela, entre otros), en los que prime el uso del diálogo afectivo y la comunicación empática y simétrica; que motive la realización personal y la formación de individuos estables, con la disposición para adaptarse a los desafíos inherentes a la resolución de sus necesidades emocionales. Entre estas se precisan: la flexibilidad para negociar, la disposición para reconocer al otro y el de- sarrollo de vínculos de interdependencia que propicien la convivencia pacífica.

Para Tedesco (2000), la dimensión socioemocional y afectiva del ser humano requiere, para ser consolidada oportunamente, del concierto de ciertas condiciones relacionadas con ajustes a nivel familiar; en el que deben incrementarse la carga afectiva que fortalezca la vida en el hogar, se estrechen lazos de confianza y solidaridad que impulsen "la autoexpresión, el respeto por la libertad interna, la expansión de la personalidad y de sus cualidades, y su excepcionalidad; es decir, disponer del derecho a crear o construir una forma de vida abierta y sin trabas" (p.45).

En suma, la crisis que experimenta el mundo en lo social, efectivo y emocional requiere del fortalecimiento de los factores de socialización, en especial de la familia como "la primera formadora de hábitos, valores, $y$ actitudes, que la educación luego se encarga de reforzar en estrecha consonancia con el desarrollo humano al menos en las primeros años de formación del ser humano" (Sartori, 2005, p.2). Esto implica no solo atender la dimensión ética-formativa, sino procurar niveles de autonomía personal, responsabilidad por sus acciones y la búsqueda del equilibrio integral como procesos inherentes a la educación emocional.

\section{c. Dimensión vocacional y profesional}

Promover el descubrimiento y la consecución de los intereses ocupaciones y laborales, se encuentra estrechamente vinculado con la 
búsqueda de posicionamiento social; parafraseando a Fromm (1956), la tendencia natural del ser humano consiste en alcanzar el éxito, erigirse como una persona digna; gozar de reconocimiento por sus competencias y habilidades, las cuales se encuentran asociadas con el logro de la felicidad y la plenitud. Para Freire (1999), las políticas educativas deben enfocarse no solo en formar para la vida, sino para perfilar posibles preferencias ocupacionales que le permitan "la libertad para asumir las riendas de su destino, posibilidad de decisión, de elección y de autonomía para dar cumplimiento a su vocación" (p.13). Al respecto, la perspectiva humanista reafirma que, "el ser humano es libre, y tiene el dominio de conocer, de razonar, de su capacidad de elección y decisión de acuerdo a un proyecto de vida con valoraciones definidas" (Daros, 2009, p.147).

Martínez (2009), refiriéndose a la orientación efectiva, propone la necesidad de promover la exploración de preferencias vocacionales $\mathrm{y}$ actitudes profesionales en todos los niveles educativos; es decir, motivar la autorrealización personal y la definición de proyectos de vida que dirijan la estructura ocupacional del individuo. De este modo, la orientación vocacional y profesional se convierte en dimensión del desarrollo humano, que requiere de la actuación del docente y el acompañamiento psicológico en función de las siguientes actividades: "relaciones interpersonales de ayuda, exploración de las cualidades personales, nivel de afinidad con sus metas vocacionales y posibles proyecciones" (p.133).
Al respecto Bisquerra (2006), reitera que la orientación vocacional es un proceso continuo, de ayuda con el que se pretende en el sujeto el desarrollo criterios, defina su identidad vocacional y logre sus objetivos personales; se trata de guiar al ser humano en la definición de su carrera profesional, en la consolidación de actitudes y aptitudes, intereses vocacionales que les permitan insertarse en un mercado laboral con efectividad y compromiso. Más adelante, Bisquerra y Pérez (2007) proponen que la orientación vocacional cuenta con bondades específicas como: capitalizar las habilidades en torno a una ocupación, capacitar para el ejercicio de actividades de modo efectivo e incrementar las competencias de desempeño en atención a los criterios de eficacia, eficiencias y productividad, como aspectos inherentes al desarrollo humano que al ser potenciados generan a su vez bienestar socio-personal.

En suma, atender la dimensión vocacional, según expone Sabino (2004), constituye un proceso complejo, asociado con "el incremento de la competitividad y la apertura de nuevas oportunidades dentro del mercado laboral; pero con la apertura a posibilidades de empleabilidad, que multipliquen la realización multidimensional del ser humano" (p.6). Frente a este desafío, generar crecimiento global y holístico requiere impulsar la formación de emprendedores, de sujetos capaces de defender sus preferencias y actitudes laborales, en función de las cuales garantizar su ingreso eficaz y productivo dentro del escenario social global, del que solo es posible partici- 
par si se dispone flexiblemente al cambio; se adopta la actualización y el aprendizaje para potenciar las competencias que demandan un mundo movilizado por la globalización. Ante este escenario es posible actuar "mediante el dominio de cualquier arte, este dominio es de fundamental importancia para lograr el éxito, el prestigio y la energía para para descubrir la forma de alcanzar los objetivos personales" (Fromm, 1956, p.22).

\section{d. Dimensión educativa}

La educación para el desarrollo ha contado con la integración de apreciaciones y posturas disciplinares de diversa índole. Para la teoría crítica representa un proceso mediado por acciones e intervenciones simétricas, a través de las cuales pueda generar autonomía en el ser humano y transformar su pensamiento; de manera que logre trascender las imposiciones ideológicas tradicionales y construir su propia forma de entender la realidad (Freire, 1999). En este sentido, educar al ser humano involucra la tarea de humanizarlo (Pérez, 2005), de desarrollar su conciencia y la reflexión crítica que le permita orientar sus acciones de modo responsable.

Maturana (1990), en un intento por responder a la interrogante ¿para qué sirve la educación?, plantea las siguientes ideas: educar es insertarse en un proyecto de vida personal y de responsabilidad social. Es un modo de combatir las desigualdades y de sensibilizarnos frente a las necesidades de otros, pero también de defender con cordura los objetivos personales; educar ayudar a descubrir el sentido de lo hu- mano y actuar en función de ello en nuestras acciones cotidianas. En razón de estas premisas, el autor afirma que "la educación no es más que un proceso continuo que entrelaza lo emocional con lo racional" (p.7).

Educar es también, motivar el aprendizaje a lo largo de la vida y desarrollar las competencias emocionales para ejercer autocontrol frente a los conflictos cotidianos, en los que deberá poner a prueba el manejo de actitudes tolerantes. Para Torres (1999), educar para el futuro no es más que "promover cualidades tales como la creatividad, la receptividad al cambio y la innovación, versatilidad en el conocimiento; adaptabilidad a situaciones cambiantes, actitud crítica e identificación y solución de problemas" (p.3).

Desde la perspectiva cognitiva, la educación del ser humano debe enfocarse en acompañar y orientar en "la construcción de la realidad, para adaptarse mejor al mundo y asumir activamente la responsabilidad de cambiarlo" (Bruner, 1997, p.25). Para Daros (2009), la educación cuenta con fines específicos desde el punto de vista social, entre los que menciona no solo su formación para accionar sobre su realidad por sí mismo, sino "la integración del individuo con los demás, con las pautas sociales que le dan continuidad a la vida colectiva y a la convivencia humana” (p.23).

Sarramona (2002) afirma que la educación de calidad como requerimiento para el desarrollo humano integral, debe potenciar varias dimensiones, entre las que destaca "establecer un modelo que promueva la edu- 
cación intercultural, el establecimiento de valores morales, vincular de modo directo con el mundo laboral y propiciar la configuración positiva de la personalidad" (p.29). Para Zimmermann (2013), reitera que la educación en el presente siglo debe integrar varios aspectos, entre los que destaca: cambio de la mentalidad pasiva hacia formas autónomas de pensamiento; modificar nuestras actitudes tornándolas empáticas $y$ altruistas e insertar al ser humano en un sistema de valores éticos y morales, que den lugar al desarrollo pleno e integral.

Para Camps (2000), la educación como derecho universal toma pertinencia en medio de una sociedad sumida en la crisis, el caos y la incertidumbre; por ende, en ella reposa "el derecho de construir un proyecto de vida personal, orientado a ser feliz (libertad), a vivir en igualdad y con las mismas posibilidades de calidad de vida y apego a la dignidad" (p.2). Este énfasis en la educación como alternativa para el desarrollo individual apunta la idea de una sociedad en condiciones de organización $y$ orden; en las que funcionen oportunamente las instituciones educativas y posibiliten el estado de bienestar, el acceso a los bienes y servicios y se garantice derechos fundamentales como: la libertad, el trato equitativo, la educación con pertinencia social, sistemas de salud, empleo y educación cónsonos con los avances globales.

Cabe destacar que, las políticas públicas en materia educativa precisan no solo la atención de las debilidades y carencias sociales, sino que, en su proceder estratégico trata de "generar interacciones, relaciones de cooperación y unificación de esfuerzos entre los sectores (actores sociales) y los problemas; procurando de este modo abordar integral y multidimensionalmente situaciones que ameritan ser transformadas para establecer el bienestar integral" (Morín, 2011, p.8). Para el humanismo, este bienestar refiere a que el hombre es capaz por sí mismo de escoger los medios y fines, así como labrar sus los objetivos para alcanzar no solo su perfección y plenitud humana, sino encontrar la dignidad y la autonomía para darle cumplimiento a sus proyectos de vida (Daros, 2009; Maslow, 1954; Rogers, 1989).

Para Savater (1997) la educación del ser humano no implica exclusivamente desarollar su aparato cognitivo para que logre niveles de pensamiento crítico y aprendizaje significativo; se trata en sentido estricto de "aprender a pensar sobre los que se piensa con actitud reflexiva, como fundamento de la humanización efectiva, que potencia el actuar social, el intercambio de sentidos y la adopción de prácticas culturales reconocidas y aprobadas en atención a principios morales y éticos" (p.18). En consecuencia, la tarea de la educación debe ser formar al individuo para interactuar con el medio social; pero, además, para desarrollar aptitudes, competencias emocionales y la conciencia social para responder a las demandas del entorno en el que se hace vida. Esta posición coincide con la pedagogía crítica, que asume a la educación como el proceso liberador 
del potencial humano, cuyos fines "buscan la construcción de una sociedad más justa y equitativa" (Freire, 2002, p.1).

En este mismo orden de ideas, Pérez (2005) plantea los desafíos que enfrentan la educación y su ineludible rol social, al que define como "educar es construir personas, es cincelar corazones, ofrecer los ojos para que el educando pueda mirarse en ellos; verse valioso y bueno, y ser capaz de mirar a los demás con una manera cariñosa, inclusiva; sembradora de ganas de vivir" (p.4). Educar es, entonces, generar convicción de cambio y de superación; es transformar el ser, es recuperar su dignidad y volverlo más humano, más sensible a la realidad social. En la que debe construir con la disposición de su esfuerzo y la solidaridad, condiciones de desarrollo en las que, según el mismo autor, "se aprenda a vivir, disfrutar la vida, a defender la vida, a combatir todo lo que amenace la vida" (p.9).

En palabras de Tedesco (2000), educar en el presente siglo es una tarea compleja, que parte de formar el sentido de solidaridad y cooperación como condiciones fundamentales para "asegurar la cohesión social y la equidad necesarias para el desarrollo local sustentable" (p.64). Este compromiso formativo alude al desarrollo de la identidad y del potencial humano que, asociado a sentido de pertenencia, ayude en el proceso de permitir que afloren las capacidades para construir condiciones ciudadanas dignas; adheridas a objetivos sustentables que fortalezcan el aprendizaje para la vida y el logro de metas inherentes a los desafíos de un mundo globalizado.
En tal sentido, educar para la vida constituye una premisa suficientemente discutida desde diversas miradas científicas. Al respecto, la propuesta realizada por Maturana (1990), reitera que educar no es más que preparar al ser humano para convivir en sociedad, respetar la diversidad y actuar con empatía social, como condiciones necesarias para actuar en atención a "propósitos colectivos en los que demuestre su sensibilidad frente al otro; pero, además, su disposición para definir acciones que propicien el desarrollo propio y bienestar común" (p.8). Para la pedagogía crítica, lograr los cometidos mencionados exige la formación de un ciudadano capaz de asumir "con responsabilidad su función social, teniendo en cuenta parámetros que contribuyan a que el hombre sea cada vez más hombre, más participativo" (Freire, 2002, p.1).

Desde una mirada igualmente importante y profundamente promovida en la actualidad, se asume la educación emocional, a la que se entiende como una educación para la vida y el bienestar en sus dimensiones personal y social; cuyo propósito es "el desarrollo humano, para hacer posible la convivencia y el bienestar. Se trata de formar en competencias emocionales como competencias básicas para vida, razón por la cual deberían integrase como parte de las prácticas educativas" (Bisquerra, 2009, p.158). Por su parte, la inteligencia emocional ha propuestos las estrategias para lograr calidad de vida, entre ellas: asumir con responsabilidad la exploración de las propias capacidades y reconocer las mismas en los más cercanos; fomentar la adaptación 
al cambio y la identificación de posibles acciones para enfrentarlo con actitud positiva; énfasis especial en la formación continua y en la práctica (vivencial), y asumir diversos roles para valorar desde múltiples perspectivas las situaciones cotidianas (Goleman, 1998).

UNESCO (2015) entiende que la educación de calidad es aquella que procura dimensionar y atender, no solo las exigencias sociales sino la transformación del ser humano, al acercarlo al desarrollo de sus potencialidades $\mathrm{y}$ al cumplimiento de sus proyectos personales sin ninguna limitante. Esta educación incluye la adopción de hábitos, el despliegue de operaciones mentales y de competencias críticas para participar en la formulación de acciones (oportunidades), que lo impulsen a la autonomía y a la generación de capacidades productivas afianzadas en el desarrollo sustentable.

En resumen, la educación como eje transversal del desarrollo humano debe, desde una perspectiva amplia, cooperar con el abordaje de los principales problemas que aquejan al hombre, entre los que se precisan: la minimización de las desigualdades derivadas del recrudecimiento de la exclusión social, a la que se le atribuye la imposibilidad para lograr propósitos trascendentales para el individuo como su autorrealización; la consolidación de su potencial y el complimiento de sus objetivos personales y vitales. En tal sentido, la tarea de las agendas educativas globales requiere una significativa reformulación, que enfrente estratégicamente obstáculos para el desarrollo humano integral como: la masi- va deserción escolar, la interrupción forzosa de la educación por limitaciones económicas y la reducción de oportunidades educativas formales e informales, como aspectos que históricamente han posibilitado no solo el incremento del analfabetismo, sino la minimización del capital social necesario para impulsar el crecimiento multidimensional de cualquier país.

\section{e. Dimensión moral y ética}

Educar en valores como eje transversal refiere, entre otras cosas, a la adopción de los principios éticos y morales fundamentales para consolidar relaciones sociales sólidas y civilizadas. Camps (2000) defiende que el bienestar del ser humano requiere de procesos educativos en los que se delineen comportamientos éticos, como "el auto-dominio, la templanza, la comunicación simétrica, el diálogo no violento y la resolución pacífica de conflictos" (p.1). Para la autora, lograr mayores niveles de tolerancia social, de solidaridad y responsabilidad demanda la participación conjunta y sinérgica de los factores de socialización (familia-escuela), quienes deben constituirse en garantes de "la ética de la comprensión como medio para tratar con la indiferencia frente al otro, la incomprensión entre cultura y cultura y el egocentrismo" (Morín, 2011, p.16).

En tal sentido, las acciones que se deben adoptar para desarrollar conductas éticas se entienden inherentes a la educación y a su responsabilidad pública de formar ciudadanos idóneos moralmente; capaces de actuar con apego a los principios del bien común y 
con la actitud reflexiva para aportar al mejoramiento de la sociedad de la que es parte. Camps (2000) asume que este proceso educativo debe estar sustentado sobre tres pilares fundamentales, a decir: la enseñanza de cualquier contenido debe integrar (transversalizar) a la ética según sea el caso; la enseñanza de la responsabilidad ética debe reunir dos aspectos: principios éticos y las consecuencias derivadas de su transgresión; y, por último, la moral y la ética deben impactar en la modificación de los estilos de vida, en la recuperación de la dignidad humana y en el desarrollo de una conciencia crítica.

En consecuencia, frente a la crisis de valores que experimenta la sociedad en general, la educación se erige como la alternativa para minimizar sus repercusiones, posibilitando que en medio de situaciones contrapuestas que motivan la pérdida de principios éticos y morales, se formulen acciones pedagógicas que garanticen la integridad personal y mayores niveles de equidad y justicia social. En apoyo a esta posición, Sarramona (2002) propone que la educación moral debe perseguir la adopción de valores que impulsen al compromiso, tanto personal como social; es decir, procurar la recuperación de "ideales colectivos mantenedores de los logros más loables de la democracia: libertad, honradez, colaboración, solidaridad, responsabilidad, capacidad de sacrificio, aceptación de la norma emanada de la autoridad legal" (p.91).

En atención a lo anterior, debe entenderse a la educación moral como la búsqueda sistemá- tica de la libertad humana dentro de los principios de igualdad, solidaridad, bien común y equidad, los cuales deben ser integrados a la sociedad como reglas de conducta que -por sus implicaciones- posibilitan la creación de ambientes sustentados en el respeto, el reconocimiento del otro y la erradicación de la confrontación. Esto indica que, todo proceso educativo debe desplegar sus esfuerzos hacia la consolidación de "la integración social, la ruptura con el aislamiento y el desarrollo de conexiones culturales; la búsqueda persistente de la asociación y unificación de esfuerzos que garanticen el cumplimiento del interés general (Morín, 2011, p.7).

Por su parte, Sen (2000) reitera que solo la vida en sociedad nos ayuda a transformarnos en seres completos y plenos; tesis en la que subyace que, en caso contrario "la independencia de otros no solo plantea problemas éticos sin que, además, es derrotista en la práctica; ya que mina la iniciativa y el esfuerzo individual y la dignidad personal" (p.339). En tal sentido, solo es en la dimensión social y en la interacción con otros que se genera el desarrollo equilibrado del individuo, pues es allí donde se aprenden hábitos de vida y afloran las virtudes que definen modos de vida apegados a la moral.

Savater (1997) alude a la formación ética como una función educativa que procura establecer límites a las apetencias y restringir los propios comportamientos que pudieran alterar la convivencia social, así como vulnerar la integridad de terceros. Es así que, la ética se 
asocia con el respeto por los semejantes como interés vital, que debe regir las relaciones cotidianas y la conciencia social que integran y posibilitan el funcionamiento equilibrado del individuo. A esta postura sobre la ética, Montero (2004) la denomina integrarse "al interés común por encima del bienestar individual; es reconocer el carácter humano y digno del otro, pero también, respetar su condición de igualdad, sus derechos y obligaciones" (p.46).

Cortina (2000) se refiere a la educación ética como la filosofía práctica, la cual involucra propósitos tales como "despertar directamente actitudes porque se consideran más humanas o más cívicas; orientar al hombre en la tarea de definir los modos de convivencia más idóneos y explicitar los mínimos morales, valores y hábitos que una sociedad democrática debe transmitir" (p.17). A partir de esta posición, es posible afirmar que la vida social por sus implicaciones, así como por la continua emergencia de situaciones conflictivas, requiere de comprender que la realidad humana debe regirse por normas, principios y valores que estructuren la convivencia, las acciones y las actitudes idóneas para fortalecer la convivencia social.

Para Tedesco (2000), la dimensión ética y moral corresponde a la base fundamental de las relaciones sociales positivas, pues esta define el establecimiento de límites de las actuaciones humanas y la orientación de comportamientos apropiados, que garanticen la adopción de valores que definen la capacidad para vincularse sin transgredir el espacio y derechos del otro. El autor indica que estos valores se transmiten fundamentalmente en el escenario familiar, y luego la escuela debe encargarse de reforzar el repertorio moral que la sociedad requiere; apuntando hacia el tratamiento y la praxis de valores como "la honradez, el rechazo a la discriminación y la eficacia del pensamiento autónomo, el reconocimiento a la libertad individual, el compromiso social y la aceptación de la diversidad" (p.46). Lo que para la perspectiva humanista de la psicología serían requerimientos inherentes a la autorrealización, capaces de fortalecer y elevar los estándares éticos y la adopción de comportamientos cónsonos, con las pautas y valores sociales que configuran la vida en comunidad (Cloninger, 2003).

En síntesis, garantizar la vida en sociedad requiere de esfuerzos mediados por políticas educativas, capaces de orientar al ciudadano en el aprendizaje de referentes morales comunes que posibiliten la convivencia pacífica y minimicen el estado de conflictividad que embarga el mundo. Lograr estos cometidos demanda la enseñanza del diálogo activo y las bondades de la comunicación asertiva como aspectos que integran la conducta moral; potencian la tolerancia y garantizan el respeto pleno a la diversidad. Desde la perspectiva de Morín (1999), se trata de una enseñanza ética que despierte en el ser humano "la conciencia de ser parte de una sociedad, que debe ser respetada, como exigencia inherente a la ciudadanía terrestre" (p.3). 


\section{f. Dimensión salud, bienestar físico y biológico}

En la defensa de esta dimensión, ubicamos las apreciaciones de Bisquerra (2009), para quien el bienestar del ser humano se encuentra determinado por varias condiciones, entre las que precisa vivir en un entorno confortable que aporte salud en lo físico, social y psíquico. Atender esta dimensión propone el desarrollo cualitativo y equilibrado que le permita al individuo alcanzar niveles óptimos de autorrealización y de interacción con el contexto social, en el que se espera logre enfrentar los factores que atentan contra el bienestar integral. Desde una perspectiva amplia, esta dimensión procura que el ser humano alcance el crecimiento multidimensional en "su aparato físico, emocional, espiritual, psíquico y social; contando de este modo con las condiciones necesarias para enfrentar enfermedades, así como realizar competitivamente las actividades diarias" (p.279).

Esto implica maximizar los factores que determinan la esperanza de vida, entre las que se precisan el entrenamiento disciplinado y sistemático, la adopción de estilos de alimentación saludables y la reformulación de las prácticas de consumo; así como la ruptura de hábitos sedentarios que impulsen el desequilibrio funcional y la alternación de las funciones biológicas del cuerpo humano. Ello, desde la educación para la salud, supone la ayuda permanente y el establecimiento de programas de orientación que le indiquen al ciudadano - según sus particularidades- cuáles hábitos nutricionales suprimir; los que deberá adoptar y los que necesariamente reformular para garantizar su funcionamiento social integral.

En otras palabras, se trata de garantizar que la población se adapte a patrones de consumo conscientes y disciplinados a lo largo de su ciclo vital. Esto involucra la participación del Estado como garante de la salud integral, en quien recae la responsabilidad de generar políticas que prioricen el bienestar físico y biológico, partiendo desde la integración de una educación sustentable, que promueva la producción y consumo de productos orgánicos y la sustitución de prácticas nocivas que atentan contra el funcionamiento apropiado del sistema humano. Además de la degradación de las condiciones ambientales y de los ecosistemas que determinan el equilibrio natural de la naturaleza, como dimensión que nos provee los insumos fundamentales para elevar la calidad de vida.

Por ende, se procura que el ser humano consolide su sensibilidad para asumir, desde la educación para la salud, las exigencias y propósito en función de los cuales garantizar la interrelación con sus pares de manera satisfactoria; asumiendo patrones de consumo saludables y estilos de vida libres de inactividad física, y del consumo de sustancias (drogas, alcohol, entre otras) - que por sus efectos - condicionan o alteran el normal funcionamiento del organismo y ponen en riesgo la salud. En palabras de Martínez (2009), se propone que el bienestar físico y biológico precisa de la intervención de la educación para la salud, 
así como "de una alimentación balanceada, rica en proteínas, minerales, carbohidratos y vitaminas, que permitan el fortalecimiento del sistema inmunológico y el desarrollo cerebral" (p.123). En suma, se hace pertinente que se integre al ser humano en prácticas alimentarias saludables, que potencien su calidad de vida y dimensionen el funcionamiento integral de los sistemas que lo componen $\mathrm{y}$, de los que depende su longevidad en condiciones apropiadas.

\section{g. Dimensión social}

Para Ortega y Gasset (1954), el hombre logra alcanzar su estado de plenitud en la medida en que convive y se relaciona con otros; es decir, en que se da "el trato entre dos o más vidas que definen formas de convivencia, de comunicación y respeto que delinean reglas de comportamiento e interacción" (p.5). Esta concepción sobre la dimensión social implica - entre otras cosas - que el hombre no solo se hace así mismo en su interacción con la sociedad, sino en el manejo de las circunstancias desde una posición activa, que le invita a reflexionar para vivir y alcanzar su sentido en el mundo.

Sen (2000), refiriéndose a la vocación socialademás de asociarla con el compromiso socialla relaciona con el sentido de responsabilidad, como cualidades que por sus implicaciones se convierten en objetivos de la educación de seres humanos competentes. De allí que afirme el autor que la vida en sociedad no solo favorece la adopción y el aprendizaje de las reglas de convivencia, sino el "desarrollo de una conciencia plena para identificar las potenciales repercusiones de nuestras acciones y decisiones" (p.339).

\section{h. Dimensión ciudadana}

Castillo (2012) indica que la educación, por ser un mecanismo de transformación social, debe entenderse como una fórmula para reestablecer el equilibrio necesario para lograr bienestar el humano. Ello implica adaptarse al cambio (Delors, 1996) y adecuarse al cumplimiento de las normas y exigencias sociales que demandan de su participación en los asuntos públicos; además de orientar que su función como miembro de la sociedad le demanda su integración y el compromiso en la generación de cambios.

En palabras de Barrios (2008), la educación ciudadana responde a principios fundamentales que procuran desarrollar competencias básicas en el ser humano, que le cooperen en el proceso de impulsar la construcción de espacios democráticos. En atención a esta exigencia, se mencionan los siguientes principios: convivencia solidaria sustentada en el reconocimiento y tolerancia a la divergencia ideológica; respeto por la diversidad en todas sus manifestaciones e integración y cohesión social como requerimientos para unificar esfuerzos que promuevan el bienestar colectivo. Esto, como lo indica la autora, requiere "la formulación de programas y el establecimiento de políticas adecuadas de estímulo y garantías que motiven una mayor participación de la sociedad civil en estas tareas" (p.15). 
Durante las últimas décadas, la formación ciudadana se ha relacionado con los procesos de alfabetización como proceso inherente al manejo y comprensión de los elementos sociales y culturales, a partir de los cuales desarrollar mayores niveles de tolerancia y aceptación de la diversidad. Entender al otro pasa por el conocimiento de sus prácticas culturales, sus valores y su cosmovisión sobre el mundo; condiciones que favorecen la adopción de comportamientos cónsonos que no transgredan las reglas particulares de otras agrupaciones, y "que reconozcan las variaciones que están inmersas en formas sociales de organización de la actividad humana" (Rogoff, 1993, p.12).

Para la psicología sociocultural, lo anterior no es más que el resultado de la flexibilidad del pensamiento, que le permite abrirse al reconocimiento de otros sistemas de valores (Newman, Griffin y Cole, 1991); así como responder a situaciones conflictivas desde una actitud solidaria y tolerante, capaz de asumir - desde la perspectiva del otro - la comprensión y el abordaje de problemas cotidianos.

Ofrecer apoyo y proceder con apego altruista, pro-social y empático como requerimientos de la cultura de paz y de la resolución pacífica de conflictos a los que refieren la educación para la ciudadanía mundial (Morales, 2020b; UNESCO, 2015).

Para Delors (1996), la educación para convertirse en ciudadano del mundo debe responder a exigencias específicas relacionadas con el desarrollo de la voluntad y la disposición para vivir juntos; ser solidarios y respetar la diversidad cultural y los valores que le caracterizan. Por ende, atender esta dimensión implica "respetar las particularidades de los individuos y grupos humanos, partiendo de la reciprocidad y del reconocimiento de reglas comunes. Este reto se reduce a transformar la diversidad en un factor positivo para desarrollar una ciudadanía activa y consciente" (pp.55-56). Se trata, entonces, de erradicar la discriminación como detonante de la crisis y promover vínculos sociales fuertes que reconcilien las diferencias, y se conviertan en focos de encuentro para la aceptación y el reconocimiento como requerimientos necesarios para conducirse como un ciudadano genuino.

\section{i. Dimensión jurídica}

Desde una mira amplia, el desarrollo humano se encuentra sustentado no solo desde el enfoque económico que procura la satisfacción de necesidades materiales o fisiológicas, sino que es mucho más amplio al considerar derechos humanos como la libertad política, de asociación económica y de organización social; así como "de la oportunidad para ser creativos y productivos para disfrutar de la autorrespeto personal como aspectos inherentes al bienestar del ser humano" (Delors, 1996, p.87).

Lo anterior refiere - entre otras cosas - a la educación ciudadana como la encargada de promover no solo el proceder ético y moral, sino la asunción de una postura activa, capaz de defender los derechos humanos y las condiciones básicas para la convivencia pa- 
cífica; la autorrealización personal, social y profesional como aspectos necesarios para el desarrollo humano integral, y cuyo respaldo se encuentra en todos los tratados y convenciones internacionales que rigen la materia. Al respecto, Barba (1997), refiriéndose a la Declaración de los Derechos Humanos, indica que esta reconoce una serie de aspectos que sustentan la dimensión jurídica, a decir: el reconocimiento de la dignidad, la paz y la igualdad por parte del Estado; pero además, el ejercicio de los mecanismos necesarios para garantizar una vida con apego a la ética global, al respeto irrestricto a la diversidad en sus manifestaciones y al pluralismo de pensamiento para disentir, exigir y proponer nuevas alternativas que redunden en el desarrollo humano integral.

Estos principios aluden a principios democráticos que resguardan la convivencia social y cultural, el reconocimiento de las minorías y la promoción de valores morales compartidos que favorezcan la cohesión de la humanidad; y que reivindican la consolidación de una personalidad responsable, autónoma y con la disposición para regirse socialmente mediante la praxis de preceptos jurídicos, democráticos y del bien común. Esta educación para el entendimiento - refiere a su vez - al manejo de alternativas pacíficas para resolver conflictos y al uso de las bondades de la cultura de paz para prevenir confrontaciones sociales.

\section{j. Dimensión comunitaria}

Intervenir competitivamente en el escenario social inmediato constituye uno de los co- metidos de la educación para la ciudadanía mundial (Morales, 2020a). Al respecto, Daros (2009) asocia la vida comunitaria con el desarrollo humano, al afirmar que en este espacio se dan relaciones que preparan al individuo para la convivencia, la interacción social y la asunción de roles de liderazgo. En tan sentido, referirnos al progreso humano exige la formulación de políticas que eduquen a la comunidad en la tarea de "desarrollar capacidades para una participación más efectiva y directa en el acontecer del país, como requerimientos en los que subyace el cultivo del sentido cívico y preparar al ciudadano en los principios del bien común" (p.24).

Tedesco (2000), refiriéndose a la educación para la vida en comunidad, propone que esta debe afianzarse sobre principios como "la disposición para la convivencia, las relaciones cara a cara, con la posibilidad de ofrecer un diálogo directo, el intercambio efectivo de propuestas y el manejo del consenso para conectarse con los problemas colectivos" (p.69). Se trata de involucrar al ciudadano en protagonista de su propio cambio, en el creador de una estructura social equitativa y solidaria, $y$ en la formulación de acciones que se traduzcan en proyectos productivos, en los que se incluyan las iniciativas individuales que dimensionen el desarrollo humano integral.

Montero (2004) propone que educar para la vida comunitaria es sensibilizar al ciudadano para que asuma la responsabilidad de gestionar la resolución de sus problemas, el abordaje de sus conflictos y su trascendencia práctica, 
como requerimientos para generar desarrollo humano integral. Desde esta perspectiva, el trabajo comunitario busca integrar al ser humano "respetando las diferencias individuales, en lugar de excluir. La comunidad como grupo organizado tiene voz propia, y sus miembros activos cuentan con capacidad para tomar y ejecutar sus propias decisiones, tienen la capacidad y el derecho de participar" (p.46).

Refiriéndose a las políticas públicas, la autora reitere que estas representan acuerdos entre el Estado y la comunidad (sociedad). Es la esfera en la que se ejecutan, se dan acciones y se promueven las relaciones entre individuos, a partir de las cuales se "diseñan líneas de acción, generan espacios para el diálogo y para la formulación de estrategias transformadoras, que respondan a una proyección activa del individuo en su medio ambiente social" (p.49). En consecuencia, educar para la vida comunitaria no es más que una estrategia para garantizar la creación de un sistema social, fundado en la democracia participativa y en la unificación sinérgica comunidadinstituciones políticas, como requerimientos clave para consolidar cambios coyunturales y trascendentales.

\section{k. Dimensión tecnológica y comunicacional}

La disminución de la brecha digital se ha considerado desde todos los ámbitos y, en especial, desde la política y la educación, objetivos de todos los programas de gobierno en el mundo entero. Si partimos de la propuesta de Sartori (2007), la sociedad está inmersa en un sistema complejo de interrelaciones nuevas, contenidos complejos y modos de como circula la abundante información que se produce día a día. Por esta razón, se está frente a un nuevo factor socialización denominado sociedad de información y comunicación, que exige el acompañamiento de quien se forma con la finalidad de evitar "el empobrecimiento del aparato cognoscitivo, y en su lugar, motivar la reflexión del mundo, el uso del pensamiento y la capacidad para articular ideas claras y diferentes" (p.2).

En atención a esta propuesta, es responsabilidad de la educación acercar al ciudadano al manejo de las tecnologías, disponiéndolas para desarrollar competencias investigativas, habilidades de lectura crítica y capacidades de generalización y abstracción. Por ende, las políticas públicas en materia educativa deben promover el uso de las competencias tecnológicas para desempeñarse con solvencia en una sociedad informatizada, en desarrollo y constante transformación, con el propósito integrarlo activamente en la resolución de los problemas sociales como respuesta a la formación ciudadana. De esta, a su vez, depende que su proceder sea cabal y participativa para proponer alternativas; responsable y consciente para accionar desde el pensamiento científico y lógico, así como consumidor consciente en lo que respecta al uso de los recursos (Gay y Ferreras, 2002).

En consecuencia, el acceso al conocimiento y a la información constituye un derecho humano, que le permite al individuo apropiarse al saber especializado desde una perspectiva 
globalizadora, actualizada y pertinente. Este desafío político y educativo implica "la reforma del pensamiento para afrontar e integrar informaciones pertinentes, relacionar conocimientos separados y comprender el conocimiento complejo desde una actitud reflexiva" (Morín, 2011, p.159). Esta posición es igualmente compartida por Tedesco (2000), al reiterar que disponer de fuentes informativas, coadyuva con el desarrollo del pensamiento, creatividad y libertad, como requisitos para "abordar desde diversos puntos de vista los problemas sociales; renovar permanentemente las líneas de decisión y garantizar el logro de objetivos estratégicos inherentes al desarrollo integral" (p.12).

\section{Dimensión cognitiva, pensamiento, inte- ligencia y creatividad}

Potenciar el pensamiento significa en la actualidad, además de un desafío asociado con la educación, un objetivo global de las agendas educativas del cual depende, significativamente, la consolidación de actitudes autónomas y responsables, que favorecen el abordaje de problemas complejos y la resolución de situaciones vinculadas con la convivencia social efectiva. Según propone Freire (1999), la educación del presente siglo debe enfocar sus esfuerzos en trascender del conocimiento conjetural hacia el uso del pensamiento reflexivo, crítico y analítico; a través del cual desarrollar competencias para aprehender con rigurosidad a construir su propio saber. Esto implica orientar al ser humano para que, en uso de su consciencia, se haga "capaz de comprender, de inteligir el mundo, de intervenir en él en forma técnica, ética, estética y científica” (p.15).

Tedesco (2000), refiriéndose a los cambios que experimenta el mundo y las transformaciones que esto conlleva, propone que nos encontramos frente a una crisis estructural que sitúa a la educación en el compromiso de potenciar cognitivamente al hombre para responder a la premisa consensuada "el conocimiento y la información están reemplazando a los recursos naturales; si bien el conocimiento siempre fue una fuente de poder; ahora sí sería su fuente principal" (p.12). Entender el planteamiento sugiere que la producción de conocimiento no solo se vislumbra inagotable, sino potencialmente tendiente a la manipulación del pensamiento; condiciones que, desde el punto de vista educativo, demanda la promoción de habilidades cognitivas y de competencias críticas que posibiliten el aprendizaje significativo y autónomo.

Para Delors (1996), la educación debe cimentar sus intervenciones en desarrollar competencias cognitivas y aprendizajes fundamentales que cooperen con la formación autónoma. De allí que proponga la necesidad de integrar en toda política educativa, elementos transversales que favorezcan el efectivo desempeño humano en el contexto social; entre los cuales menciona: aprender a conocer, es decir, identificar sus propios estilos de aprendizaje y las operaciones mentales que le permitirán apropiarse del conocimiento; aprender a hacer, refiere al desarrollo de 
habilidades y destrezas que le cooperen en el proceso de intervenir y transformar su realidad; aprender a vivir junto, exige el manejo de competencias sociales que ayuden a resolver problemas mediante el uso del diálogo, la comunicación asertiva y la negociación; $y$, aprender a ser, encierra los anteriores y procura que el sujeto alcance no solo la autorrealización, sino la adopción de actitudes éticas y morales en su interacción social.

Desde la perspectiva de Martín y Martín (2013), promover la creatividad y el pensamiento divergente implica integrar al ser humano en el rol activo de procesar de modo autónomo información, propiciando la generación de nuevas ideas y la motivación por la producción de conocimiento como insumos a partir de los cuales resolver situaciones complejas y problemas cotidianos. Se trata de facilitar las condiciones para la exploración de alternativas innovadoras y el desarrollo de la capacidad inventiva, como manifestaciones propias que definen su disposición y la flexibilidad cognitiva para formular respuestas ante una demanda determinada (Corkille, 1970; Morales, 2020d; Rogers, 1996); mediante la organización de aspectos independientes y aparentemente inconexos, que al ser asociados a través del pensamiento lógico-deductivo, aportan a la resolución de problemas (Rogoff, 1993).

Meireiu (2002) postula la idea de acercar progresiva y sistemáticamente al ser humano al descubrimiento de sus propios procesos de apropiación del saber, mediante la reflexión estratégica y la gestión del aprendizaje. Para lograr tales cometidos, es fundamental que desarrolle operaciones mentales entre las que destaca: la deducción y el razonamiento lógico, la criticidad y el pensamiento reflexivo, así como la organización y sistematización de experiencias significativas. Para la autora, una actividad mental básica de todo proceso formativo requiere de la creatividad, a través de la cual el sujeto manifieste "su ser íntimo, la divergencia, a la imaginación y le dé cabida a la novedad y a la originalidad" (p.129).

En consecuencia, la dimensión cognitiva en todo proceso educativo se asume susceptible de cambio y transformación, a través de la "la interacción dialéctica entre el mundo social y el cambio individual; esto involucra la reestructuración del pensamiento, potenciar la invención promover la direccionalidad" (Newman, Griffin y Cole, 1991, p.6). Para Gutiérrez (2005), estos procesos además de aludir al desarrollo y al aprendizaje, refieren a "la internalización de los recursos, pautas e instrumentos de interacción social y, por tanto, el individuo se desarrolla en la medida en que, por su inserción en las estructuras sociales, puede aprender de los otros" (p.100).

Por su parte, Davini (2015) reitera que la dimensión cognitiva y los procesos psicológicos complejos deben ser potenciados, con el propósito de desarrollar capacidades, competencias y actitudes para la praxis; es decir, para generar acciones con el potencial para transformar el contexto social y cultural. Se trata de generar una visión profunda del mundo, 
de su recurrente cambio (Bruner, 1995) y los problemas que implica moverse en un escenario caracterizado por la incertidumbre; condiciones que exigen la disposición cognitiva para reformular acciones con ayuda de la inteligencia y sus modos de operar (Gardner, 1993; Goleman, 1998). Así como con el despliegue de las bondades del pensamiento crítico, entre las que se mencionan: la detección de contradicciones, el descubrimiento de lo no dicho y el fortalecimiento del interés emancipador como condición inherente para romper con la dominación (Freire, 1999).

Morín (2011), en su propuesta sobre cómo vivir en tiempos de crisis, deja ver que la necesidad de erradicar formas monádicas y reduccionistas de valorar el mundo "que solo han posibilitado el avance de la ignorancia, que se ve favorecida por ese pensamiento parcelado, que no ve más que fenómenos separados y permanece incapaz de comprender sus relaciones" (p.27). Frente a estas características propias de la enseñanza tradicional, el rol de la educación debe enfocarse en potenciar el pensamiento en sus modos de operar crítico, complejo y reflexivo, a través de los cuales construir generalizaciones, razonamientos y lograr contextualizar conocimientos para transformar realidades inmediatas.

\section{m. Dimensión espiritual}

Enfrentar los desafíos que impone la convivencia social y las situaciones que de esta emergen, demanda la formación y el desarrollo de habilidades emocionales, sociales, afectivas y socioemocionales; sin dejar a un lado el manejo de las bondades de la inteligencia espiritual. Para Torralba (2010), la educación para la vida debe incluir la promoción y el desarrollo de la dimensión espiritual, con el propósito de motivar que en el ser humano afloren experiencias que den cuenta de la razón de su existencia; es decir, que orienten hacia la exploración de acciones con enfoque trascendental. En otras palabras, atender esta parte del hombre no significa integrarlo en la práctica de principios religiosos o dogmas, sino en guiarlo "para preguntar por el sentido de la existencia; para tomar distancia de la realidad, para elaborar proyectos de vida, para trascender la materialidad, para interpretar símbolos y comprender sabidurías de vida” (p.5).

Lo anterior refiere a la necesidad de integrar en la educación del ser, la práctica de la inteligencia espiritual, a partir de la cual ejercer la libertad, la creación y el fortalecimiento del encuentro consigo mismo, con el autoconocimiento y la autogestión. Para algunos autores se trata de un modo de inteligencia que nos permite concientizarnos sobre nuestra posición; funciones y competencias para actuar en el mundo, así como afrontar los problemas en la actitud activa de identificar lo que subyace en los mismos, $y$ de alcanzarla excelencia, el uso del pensamiento divergente, estándares de calidad, eficacia y eficiencia como aspectos inherentes a la autorrealización personal (Rogers, 1989).

Se trata, entonces, de propiciar experiencias en las que el ser humano dimensione y potencie su capacidad para superar situaciones 
cotidianas (obstáculos y retos); entendiéndolos como procesos ricos en significados, que requieren para su resolución de la disposición ecuánime, reflexiva y valorativa para contemplar - desde el distanciamiento profundo - las posibles respuestas a eventos que procuran aportar crecimiento multidimensional. Para los defensores del trabajo en el ser y para el ser, no es más que conducir al individuo para que consolide - más allá de la racionalidad - el alcance de elevados niveles de conciencia moral para algunos, e intelectual para otros. Interpretando a Goleman (1998), en su mirada sobre el desarrollo humano, deja ver que la educación del ser interior no es más que lograr, desde un enfoque holista, un equilibrio entre lo emocional, lo espiritual y lo intelectual.

Para Morín (1999), este nivel de conciencia al que intenta acercar al ser humano le permite responsabilizarse de su proceder en el mundo, del efecto de sus acciones y de las implicaciones futuras de sus comportamientos. Por ende, afirma que "el conocimiento de los problemas claves del mundo, de las informaciones claves concernientes al mundo, se vuelve una necesidad intelectual y vital al mismo tiempo" (p.12). En otras palabras, educar en la dimensión espiritual sale de la percepción religiosa para convertirse en un proceso reflexivo, capaz de explorar otras explicaciones e identificar nuevos significados, a partir de los cuales modifica nuestros estilos de vida y las prácticas sociales, que en parte definen nuestro modo de relacionarnos con el mundo.
En suma, las políticas públicas deben considerar esta dimensión, con la finalidad de concientizar al ser humano sobre su posición en el contexto global, y fortalecer la capacidad para ajustarse a los continuos cambios; generar nuevos vínculos y procesos de integración social, mediados por el respeto, la meditación reflexiva y el cuestionamiento crítico como actitudes que posibiliten el desarrollo humano individual y colectivo; el reconocimiento a la diversidad y el uso de la inclusión del otro como agente co-constructor de escenarios de convivencia para la vida. Esto implica apropiarse de las bondades del aprendizaje reflexivo, el cual procura resolver las dificultades de adaptación, pero, además, atribuirle significado a las experiencias y reformular acciones que permitan mayores posibilidades de bienestar.

\section{n. Dimensión ecológica, sustentable y medioambiental}

Atender esta dimensión constituye, tanto para los lineamientos globales sobre la educación como para la preservación de la vida en el planeta, un requerimiento que debe ser resuelto con prontitud. Por ende, los procesos de enseñanza y aprendizaje requieren la integración de contenidos y experiencias prácticas que sensibilicen, modifiquen los patrones de consumo y los estilos de vida. Al respecto, Galagovsky (1993) afirma que "es pavoroso el nivel de contaminación ambiental de todo tipo que estamos provocando en nuestro único hábitat terrícola, caracterizado por concentración y producción de sustancias, ge- 
neración de dióxido de carbono y quema de combustibles" (p.14).

Frente a este panorama poco alentador, le corresponde a la educación generar relaciones armoniosas entre el ser humano y los procesos ecológicos vitales, procurando minimizar las prácticas irracionales y guiándole, a través de experiencias de investigación en las que se reconozcan causas, consecuencias y posibles acciones que pudieran aportar soluciones pertinentes. Esto significa formar en cultura ambiental para tratar oportunamente situaciones como "el manejo de los residuos sólidos, el agotamiento de los recursos naturales, la desforestación, el calentamiento de la atmósfera, el inadecuado uso del agua dulce y el deterioro de la condición paisajística" (Avendaño, Galindo y Angulo, 2012, p.7).

Pérez (2005) exhorta sobre la necesidad de tratar con problema medulares como la violencia contra la naturaleza, a la cual se le atribuyen acciones atroces como la deforestación, la contaminación de ríos y el calentamiento desmesurado del planeta. Estos problemas, que por involucrar la responsabilidad de todos, requieren ser tratados desde políticas educativas que paralicen la destrucción del planeta, y motiven el uso racional de los recursos y la construcción de redes de cooperación, que eviten el "ecocidio"; e intervengan en la generación de la conciencia ambiental y mayores niveles de empatía con los sistemas ecológicos (Goleman, 2009). Ello posibilitaría "un desarrollo socialmente deseable, culturalmente rico, económicamente viable y ecológicamente sostenible" (Martínez, 2014, p.1).

En este sentido, se requiere guiar al estudiante a la revisión de los orígenes y la identificación de las implicaciones derivadas del actuar irracional, ante el cual se requiere formular proyectos educativos que potencien la conciencia y el respeto por la naturaleza. Goleman (2009) agrega que modificar nuestro pensamiento constituye una salida oportuna; sin embargo, se considera más efectivo promover la inteligencia ecológica que convivir con los sistemas ecológicos, procurando alterarnos en el menor grado posible. Para Zimmermann (2013), desde la pedagogía ecológica, las políticas educativas deben integrar la sostenibilidad en los programas y estrategias de enseñanza, con el propósito de "hacer uso racional de los recursos que nos provee la naturaleza como garantía para las futuras generaciones; así como cambiar nuestra mentalidad, nuestras actitudes y patrones conductuales" (p.14).

Leff (1998) plantea, desde la dimensión ecológico-ambiental, una serie de acciones que desde el nivel gubernamental y educativo pudieran cooperar con el abordaje de los problemas que en la materia experimenta. Él plantea, a decir, establecimiento de restricciones (límites) al manejo de los recursos no renovables, cuyo enfoque es únicamente economicista; educar a la ciudadanía para que asuma por sí misma la participación autónoma en las acciones de preservación, que minimizan la excesiva intervención del Estado; promover la racionalidad ambiental, valores eco- 
lógicos y prácticas sustentables, y motivar la adopción de los principios de la ética ambiental como garantes del desarrollo de conductas cónsonas con el equilibrio de la naturaleza y la convivencia armónica con los ecosistemas.

Sarramona (2002) aporta a esta dimensión aspectos valiosos que, desde el punto de vista político y educativo, significan alternativas para programas sobre acciones políticas pertinentes, entre ellos menciona que atender problemas como la deforestación, la emisión de gases tóxicos y el alarmante calentamiento global exigen el desarrollo de una cultura ecológica, de hábitos de consumo y de la reformulación de nuestros estilos con apego a la sustentabilidad. También se debe de formar para la corresponsabilidad como condición para preservar la vida, los sistemas ecológicos y el patrimonio ambiental; formular acciones pedagógicas que involucren la educación conjunta (familia-estudiante- comunidad) con la finalidad de generar redes de cooperación en los entornos locales, que rompan con las ideas de apropiación y explotación del mundo natural; y se sustituya por coexistencia armónica con él (Maturana, 1990, p.13).

En suma, el desarrollo humano como propuesta de calidad de vida demanda la adopción de los principios del pensamiento y la inteligencia ecológica, como procesos cognitivos necesarios para emplazar al hombre a reformular sus prácticas y modos de vida consumistas, y adoptar comportamientos que no vulneren ni pongan en riesgo el equilibrio de los sistemas ecológicos. Esto implica ge- nerar procesos de aprendizaje y experiencias vivenciales en las que el estudiante interactúe de modo sostenible con las bondades de la naturaleza; teniendo en cuenta los potenciales impactos y las acciones, desde las cuales neutralizar consecuencias de elevado impacto en nuestro sistema biológico; vulnerando su equilibrio a futuro $y$, por ende, la calidad de vida en el planeta.

\section{o. Aproximación al desarrollo humano en Venezuela}

En este apartado se procura develar algunas reflexiones sobre el desarrollo humano en Venezuela, precisando algunos datos importantes derivados de organismos nacionales y supranacionales, que en su quehacer han mostrado el deterioro del bienestar y la calidad de vida durante las últimas dos décadas. Para ello se abordan tres dimensiones importantes, a decir: la esperanza de vida, el ingreso y los logros educacionales (Viola, Knol y Remes, 2014).

En tal sentido, es preciso indicar que la crisis política y social se ha agudizado durante la última década, ocasionando que los derechos sociales y económicos se vieran vulnerados sistemáticamente hasta ocasionar la minimización de los programas de atención al ciudadano. Según expone el Informe del Programa Mundial de Alimentos, pese al incremento del salario mínimo a "1,200\% desde el 2019, en el 2020 el monto llegó a 2.33 USD mensuales; cubriendo escasamente el 1.1\% de la cesta básica" (Organización de Naciones Unidas, 2020, p.4). Como consecuencia, 
el deterioro de la calidad de vida se ha dado de manera progresiva, pues el acceso del ciudadano a los servicios básicos se ha visto determinado por su limitado poder adquisitivo para cubrir aspectos como electricidad, gas, agua y transporte.

Al respecto, el Informe sobre Desarrollo Humano sobre Venezuela (2019) caracteriza la crisis social y política como un fenómeno con implicaciones multidimensionales, entre las que se precisan "el debilitamiento de la cohesión social y la confianza institucional, pues al no contar con los recursos necesarios para que las personas satisfagan sus necesidades, también se hace imposible que liberen su potencial en su vida personal y profesional" (p.1). Este mismo reporte indica que Venezuela - de 1990 hasta 2018 - sufrió un aumento de 0.638 a 0.726 , condición que la ubicó en los estándares de la clasificación mundial, como en categoría de desarrollo humano alto.

Por su parte, el reporte de la Organización de Naciones Unidas (2020) indica que, los últimos dos años han demostrado las consecuencias de la aplicación de políticas fallidas por parte del Estado venezolano, lo que ha ocasionado que el índice de desarrollo humano sufriera un ascenso de nivel alto a nivel medio. Sin embargo, datos tomados de organismos supranacionales, indican que la medición del Îndice de Desarrollo Humano (IDH) ha sufrido una alentadora mejoría durante el 2019; a decir "la esperanza de vida sufrió un aumento de 1.5 años, los años promedio de escolaridad aumentaron en 5.7 años y los años esperados de escolaridad aumentaron 2.4 años" (Informe de Desarrollo Humano Venezuela, 2019, p.3).

Con relación al proceso educativo, es preciso indicar que las condiciones socio-económicas actuales han motivado la deserción masiva de estudiantes, debido - entre otras razones - a la búsqueda de oportunidades que garanticen su supervivencia, la calidad de vida y el desarrollo integral. En el caso de educación básica, media y universitaria se estima, según el Informe de Provea (2019), que debido a la migración forzosa y a la situación socio-económica, docentes con elevada calidad formativa han dejado las aulas para buscar mejores oportunidades a lo largo y ancho de América Latina; fenómeno que ha debilitado el capital humano educativo y, por ende, la desatención en áreas específicas comociencias puras o aplicadas, orientación educativa y vocacional y educación integral.

Sin embargo, y pese a los elevados condicionamientos ideológicos que permean los programas educativos, se pueden resaltar aspectos positivos relacionados, en primer lugar, con la obligatoriedad de la educación desde los niveles iniciales (maternales) hasta el pregrado universitario. En segundo lugar, los componentes curriculares se entienden innovadores por el hecho de abordar de manera holística las necesidades socioeducativas, entre las que se mencionan: la educación multicultural, la orientación educativa con énfasis en le convivencia, la salud reproductiva responsable y el desarrollo vocacional; el cuida- 
do y preservación del planeta, los ecosistemas y el ambiente como aspectos vinculados con el vivir bien y la salud; formación en salud integral, hábitos alimenticios y estilos de vida sostenibles, fundados en la actividad física, el esparcimiento y la recreación, y la capacitación teórico-práctica que permita la inserción competitiva en el mercado laboral (Informe Ministerio del Poder Popular para la Educación, 2017).

Según el Informe Ministerio del Poder Popular para las Relaciones Exteriores (2016), las aportaciones al desarrollo humano en Venezuela parten de la potenciación de la educación, mediante la dotación de equipos tecnológicos, en aras de garantizar el desenvolvimiento de procesos inclusivos y equitativos, que motiven la formación de calidad. Este informe reporta, entre otras cosas, que durante la última década se ha dado "la entrega de 4,500,000 computadoras portátiles, con el propósito de mejorar la calidad del proceso de enseñanza-aprendizaje; a esto se suma la entrega de 100 millones de libros de la Colección Bicentenaria" (p.20). En el nivel universitario, la educación se ha visto afectada notoriamente debido, entre otras razones, a la migración forzosa de docentes a países de América Latina pues, las condiciones salariales establecidas por el Ministerio del Poder Popular para la Educación, indican que el ingreso de un docente a dedicación exclusiva es de "poco menos de cinco dólares; razón por la cual, las universidades han perdido entre $25 \%$ y $35 \%$ de los profesores activos" (Informe Derecho a la Educación-Provea, 2019, p.27).
Para el 2020, se estima que el 50\% de los docentes han renunciado a sus funciones, pues las condiciones hiperinflacionarias han devaluado el salario a poco menos de un dólar mensual; lo cual indica que, se según los estándares de clasificación mundial del desarrollo humano, se está en una posición de pobreza extrema (Organización de Naciones Unidas, 2020).

En materia de salud, las iniciativas del Estado han girado en torno a la creación de centros de atención integral a lo largo del espacio geográfico nacional, con los denominados programas Barrio Adentro que, según cifras oficiales del 2015 al 2019, lograron extenderse a cada región a través de los Médicos Integrales Comunitarios, beneficiando a "20,586,881 personas mediante la consolidación de más de 17,800 centros de salud" (Informe Ministerio del Poder Popular para las Relaciones Exteriores, 2016, p.17). Cabe destacar que, la creación de estos espacios de atención médica han contado con serias limitaciones, dado el escaso reconocimiento otorgado por las instituciones nacionales y oficiales de salud, para quienes la intervención y las metodologías utilizadas van en detrimento de la praxis profesional; que rige la medicina a nivel mundial, pues la formación académica de quienes integran estas misiones no reúne las condiciones para ofrecer atención especializada, que garantice tanto la prevención como la intervención en situaciones de riesgo sanitario.

El reporte de la Organización de Naciones Unidas (2020) expone que, la salud integral 
como dimensión fundamental del desarrollo humano ha sufrido un deterioro alarmante hasta ocasionar una crisis sanitaria; motivada - entre otras cosas - por la migración masiva de profesionales competentes y el retiro de otros en busca de ingresos, que garanticen la satisfacción de sus necesidades personales y familiares. Aunado a lo anterior, se precisa "la falta de medicamentos y suministros médicos, así como el deterioro de las condiciones de funcionamiento de los hospitales públicos" (p.4).

En su dimensión cívica, democrática y de participación social, indica el informe anterior, que derechos humanos como la libertad de expresión, la protesta pública y pacífica, y la demanda sistemática ante el aparato institucional se han consolidado en las principales motivaciones de persecución política e ideológica. De allí que, durante los dos años, se hayan registrado " 10,026 protestas, $73 \%$ de estas por el deterioro de los servicios y de los salarios; falta de combustible y la casi erradicación del poder adquisitivo del ciudadano, debido - entre otras razones - por los elevados índices inflacionarios" (p.5). Esto es respaldado por el Informe del Observatorio Venezolano de la Conflictividad, el cual indica que durante los años 2019-2020, los reclamos y protestas se incrementaron a 2,689; registrándose que sus propósitos giraron en torno al reclamo de derechos políticos y civiles.

En función de estos reportes, es preciso indicar que las limitaciones impuestas a la población y el incremento de la represión como mecanismo de control, han ocasionado desequilibrios sociales, impulsados por las deficitarias decisiones políticas que, en lugar de focalizar sus esfuerzos en potenciar el capital social mediante la interacción Estado-ciudadanía como estrategia de transformación social, han centralizado los procesos de intervención en el aparato institucional propiciando actuaciones fallidas.

Con relación a la dimensión económica, de emprendimiento e innovación, es preciso indicar que, para el año 2016, la tasa desempleo mostraba una reducción significativa, distribuida de la siguiente manera: "se generaron $4,626,867$ empleos y una disminución del desempleo en 266,868 personas" (Informe Ministerio del Poder Popular para las Relaciones Exteriores, 2016, p.26). Según indica el Informe de Provea (2019), la hiperinflación superó el “1,689,488\% devorando los ingresos familiares; lo cual se traduce en caos en los servicios públicos, trastorno de la dinámica escolar e incremento del ausentismo y deserción" (p.21). A esto se une la amenaza recurrente a la propiedad privada, el limitado acceso a medios de financiamiento y el establecimiento de controles fiscales férreos, que han ocasionado que la nación venezolana se vea sumida en una reducción sustancial de la producción nacional; impulsando la ejecución de políticas de importación con repercusiones negativas en el acceso a los bienes y servicios. Pero, además, debe entenderse que las implicaciones de estas actuaciones estatales constituyen una limitación multidimen- 
sional, que impide la concreción de iniciativas personales y colectivas.

Al referirnos a la dimensión tecnológica, es preciso indicar que, en Venezuela, las condiciones precarias de conexión a internet han ocasionado el desarrollo deficitario de actividades asociadas con la investigación, la extensión y la docencia. Al respecto, el informe de Aula Abierta (2020) indica que "Venezuela se ubicó en el puesto número 174, de un total de 176 países en lo que ha velocidad del internet se refiere" (p.6). Este mismo informe deja ver que existe una brecha tecnológica amplia, entre quienes gozan del servicio y quienes deben optar por otras alternativas, como asistir a un centro de conexiones en el que los precios son muy elevados. En el primer rango se ubica cerca de un 59.6\%, mientras que $39.5 \%$ reporta no contar con las condiciones económicas necesarias para aprender bajo la modalidad no presencial. A esto se unen las recurrentes fallas en el sistema eléctrico, ocasionando que un $80.7 \%$ se vea limitado en el cumplimiento de las asignaciones académicas.

Lo anterior, unido a las deficitarias políticas en materia nutricional, representa una de las coyunturales limitaciones por las que estudiantes han abandonado sus estudios, pues las instituciones educativas han dejado de ofrecer los beneficios inherentes al Programa de Alimentación Nacional (PAE). Se estima, según el Informe Consulta Nacional Educativa (2020), que la población estudiantil en niveles básicos (de los que se cuenta con datos), atraviesa estados de desnutrición en cifras alarmantes; a decir "para el 2017 se estimaba que un $40 \%$ no contaba con las condiciones nutricionales básicas. En el 2018, esta cifra asciende al 90\%; mientras que el 2020, el 74\% de los encuestados afirma no contar con condiciones nutricionales óptimas" (p.23).

En suma, es posible afirmar que el desarrollo humano en Venezuela constituye uno de los desafíos más complejos a los que se enfrenta el Estado; pues las condiciones descritas indican una reducción dramática de las posibilidades para que sus pobladores logren el bienestar integral y la calidad de vida. Esto sugiere la formulación de políticas públicas concretas que permitan la ampliación de las posibilidades de participación democrática del ciudadano en la resolución de sus necesidades. Esto implica la reducción significativa de la exclusión educativa, la diversificación de alternativas productivas, fundadas en el libre emprendimiento; la innovación y la comercialización sin limitaciones; es decir, en las que el ciudadano disponga su potencial al servicio del crecimiento personal y social, mediante el acceso a medios tecnológicos, programas de alta calidad y el goce de servicios funcionalmente apropiados, cónsonos y dignificantes de la condición humana.

Atender estas propuestas implica fortalecer el aparato institucional y el sentido de coresponsabilidad ciudadana, como dimensiones necesarias para configurar una nueva cultura cívica. 


\section{Conclusiones}

El carácter supra-complejo del ser humano y la necesidad de atender la multidimensionalidad, propone la adopción de cambios significativos en los programas educativos y en las políticas sociales, con la intención de garantizar el desarrollo humano y sus componentes: calidad de vida, bienestar integral y la realización del ciclo vital. Se trata de fortalecer las condiciones para que se alcance el equilibrio biopsicosocial, la promoción de habilidades personales y la adopción de formas alternativa de consumo, que den lugar al crecimiento multifacético necesario para lograr el funcionamiento competitivo de las dimensiones: física, mental, social, emocional y biológica.

Ofrecer atención a estas dimensiones impone una ardua tarea a la educación, que consiste en lograr una integración armónica de los factores externos y las condiciones internas del ser humano; a través de iniciativas de intervención multidisciplinar que potencien el desarrollo de la personalidad y de la madurez integral, posibilitando el desempeño pleno de las dimensiones que determinan el bienestar armónico y su disposición para enfrentar competitivamente - los retos derivados de su relaciones cotidianas. Ello plantea la atención a todas las dimensiones que conforman al ser humano; que debe asumirse como una acción estratégica capaz de motivar y acercarlo a la consolidación de la autorrealización personal y social.

En el caso venezolano, es preciso indicar que la última década ha representado uno de los momentos históricos más críticos, pues la inestabilidad política, la aplicación de medidas económicas y la escasa capacidad del Estado - para atender de manera sostenida las necesidades reales - se han convertido en puntos focales con repercusiones inmediatas en el desarrollo humano integral. Prueba de ello, la migración forzosa continúa en ascenso, generándose el abandono de cargos en materia educativa, de salud, entre otros; condición que se traduce en la minimización de las posibilidades de atención digna y de calidad para el ciudadano.

En suma, el desarrollo humano como objetivo de las agendas políticas y educativas del presente siglo, plantea un inminente desafío que exige del Estado y de la sociedad, la unificación de esfuerzos que permitan la creación de oportunidades en igualdad de condiciones; el tratamiento estratégico de la inclusión social, y la generación de una conciencia flexible con la disposición para enfrentar los cambios y emprender iniciativas productivas que potencien la autonomía y el sentido de co-responsabilidad.

Estos cometidos sugieren el tratamiento de áreas coyunturales como el acceso gratuito a la educación, el ejercicio de las libertades individuales y colectivas, y la consolidación de los proyectos de vida personal, mediante los cuales se alcance la autorrealización, el crecimiento multidimensional y el logro de niveles dignificados de vida y bienestar integral. 


\section{Referencias}

Aristizábal, N. (2015). Psicología cognitiva. Editorial Ltda.

Avendaño, R.; Galindo, A. y Angulo, A. (2012). Ecología y educación ambiental. Universidad Autónoma de Sinaloa.

Barba, J. (1997). Educación para los derechos humanos. Fondo de Cultura Económica

Barrios, M. (2008). Una mejor educación para una mejor sociedad. Fundación Fe y Alegría.

Bisquerra, R. (2006). Orientación psicopedagógica y educación emocional. Estudios sobre Educación, (11); pp. 9-25.

Bisquerra, R. y Pérez, N. (2007). Las competencias emocionales. Educación XXI, pp. 61-82.

Bisquerra, R. (2009). Psicopedagogía de las emociones. Editorial Síntesis.

Bisquerra, R. (coord.). (2011). Educación emocional. Propuestas para educadores y familias. Editorial Desclée de Brouwer

Bruner, J. (1995). Desarrollo cognitivo y educación. Ediciones Morata.

Bruner, J. (1997). La Educación, puerta de la cultura. Editorial Visor.

Camps, V. (2000). Los valores de la educación. Editorial Anaya.

Carballeda, A. (2012). La intervención en lo social/ exclusión e intervención en los nuevos escenarios sociales. Paidós.

Castillo, J. (2012). Sociología de la educación. Red Tercer Milenio S.C.

Cloninger, S. (2003). Teorías de la personalidad. Prentice Hall.

Corkille, D. (1970). El niño feliz su clave psicológica. Granica Editor.

Cortina, A. (2000). Ética mínima. Introducción a la Filosofía Práctica. Editorial Tecnos.

Daros, W. (2009). El entorno social y la escuela. Editorial Artemisa.

Delors, J. (1996). La educación encierra un tesoro. Ediciones UNESCO.

Elizalde, A. (2012). Desarrollo humano y ética para la sustentabilidad. PNUMA.

Flavell, J. (1992). Desarrollo cognitivo: pasado, presente y futuro. Developmental Psychology, 28, (6), pp. 998-1005. 
Freire, P. (1999). Educación y política. Siglo XXI Editores.

Freire, P. (2002). Educación y cambio. Editores Buenos Aires. http://www.elmayorportaldegerencia.com/Libros/Coaching/[PD]\%20Libros\%20\%20Educacion\%20y\%20cambio.pdf

Fromm, E. (1956). El arte de amar. Fondo de Cultura Económica.

Galagovsky, L. (1993). Hacia un nuevo rol docente. Editorial Troqvel.

Galeano, E. (1988). La escuela del mundo al revés. Siglo XXI.

Gardner, H. (1993). Estructuras de la mente. La teoría de las inteligencias múltiples. Editorial: Diegoan.

Gay, A. y Ferreras, M. (2002). La educación tecnológica. Aportes para su implementación. CONICET-Argentina.

Goleman, D. (1998). Inteligencia emocional. Editorial Kairós. S.A.

Goleman, D. (2009). Inteligencia ecológica. Ediciones B.S.A de C.V.

Griffin, K. (2001). Desarrollo humano: origen, evolución e impacto. En IBARRA, P. y UNCETA, K. (coord.). Ensayos sobre el desarrollo humano. http://otrodesarrollo.com/desarrollohumano/GriffinDesarrolloHumano.pdf

Gutiérrez, F. (2005). Teorías del desarrollo cognitivo. McGRAW-HILL

Informe Ministerio del Poder Popular para las Relaciones Exteriores (2016). Presentación nacional voluntaria (PNV) ante el Foro Politico de alto nivel sobre desarrollo sustentable (FPAN) de Naciones Unidas. http://cepei.org/wp-content/uploads/2019/10/Venezuela.pdf

Informe Ministerio del Poder Popular para la Educación (2017). Áreas de formación en Educación-Inclusión y Calidad. http://www.cerpe.org.ve/tl_files/Cerpe/contenido/documentos/ Actualidad\%20Educativa/Transformacion\%20curricular\%20EM/Areas_de_formacion_ en_educacion_media_general\%20(2)\%20(2).pdf

Informe Anual Derecho a la Educación-Provea (2019). Situación de los derechos humanos en Venezuela. Serie Derecho a la Educación.

Informe de Desarrollo Humano Venezuela (2019). Desigualdades del desarrollo humano en el Siglo XXI-República Bolivariana de Venezuela. http://hdr.undp.org/sites/all/themes/hdr_ theme/country-notes/es/VEN.pdf 
Informe Aula Abierta (2020). Afectaciones a la educación de calidad en las Universidades públicas venezolanas en el marco del covid-19. http://aulaabiertavenezuela.org/wp-content/ uploads/2020/04/AFECTACIONES-A-LA-EDUCACI\%C3\%93N-DE-CALIDAD-ENLAS-UNIVERSIDADES-P\%C3\%9ABLICAS-VENEZOLANAS-EN-EL-MARCO-DELCOVID-19-1.pdf

Informe Consulta Nacional Educativa (2020). Estado actual de la Educación Venezolana. FundaRedes. https://www.fundaredes.org/informes/consulta-nacional-educativa-2020.pdf

Informe del Observatorio Venezolano de la Conflictividad (2020). Venezuela septiembre 2020. https://www.observatoriodeconflictos.org.ve/oc/wpcontent/uploads/2020/10/INFORMEOVCS-SEPTIEMBRE2020.pdf

Jiménez, C. (2010). Calidad de vida. Biblioteca CF+S.

Lafarga, J. (2016). Desarrollo humano: desarrollo personal. Editorial Trillas.

Leff, E. (1998). Saber ambiental. Sustentabilidad, racionalidad, complejidad y poder. Siglo XXI Editores. Martín, I. y Martín, L. (2013). Creatividad y educación. Revista de Ciencias Sociales, (9), pp.311-351. Martínez, M. (2009). Dimensiones básicas del desarrollo humano integral. Polis, Revista de la Universidad Bolivariana, 8 (23); p. 119-138.

Martínez, J. (2014). Manual para la educación para el desarrollo sostenible. UNESCO. https:// www.urv.cat/media/upload/arxius/catedradesenvolupamentsostenible/Informes\%20VIP/ unesco_etxea_-_manual_unesco_casteducation_for_sustainability_manual.pdf

Maslow, A. (1954). Motivación y personalidad. Harper and Row.

Maslow, A. (2008). La personalidad creadora. Editorial Kairós.

Maturana, H. (1990). Emociones y lenguaje en educación política. Colección HACHETTE/COMUNICACIÓN CED.

Montero, M. (2004). Introducción a la psicología comunitaria. Desarrollo, conceptos y procesos. Editorial Paidós.

Morales, J. (2020a). Un acercamiento multidisciplinario al rol del docente en el contexto comunitario y educativo. Revista Conocimiento Educativo, 7, pp. 39-59. 
Morales, J. (2020b). Educación y desarrollo humano: dimensiones para la elaboración de políticas públicas en tiempos de complejidad. Revista Conrado, 16 (75), pp. 372-383.

Morales, J. (2020c). Una política pública para potenciar la calidad de vida y el desarrollo humano. Universidad de Los Andes. Revista Estado de Derecho, 2 (1), pp. 119-146.

Morales, J. (2020d). Oportunidad o Crisis Educativa: Reflexiones desde la Psicología para Enfrentar los Procesos de Enseñanza-Aprendizaje en Tiempos de Covid-19. Revista Internacional de Educación para la Justicia Social, 9 (3e).

Morín, E. (1999). Los siete saberes necesarios para la educación del futuro. UNESCO.

Morín, E. (2012). Cómo vivir en tiempos de crisis. Editorial Nueva Visión.

Morín, E. (2011). La vía para el futuro de la humanidad. Paidós.

Nardone, G.; Giannotti, E. y Rocchi, R. (2003). Modelos de familia. Conocer y resolver los problemas entre padres e hijos. Editorial Herder.

Newman, D.; Griffin, P. y Cole, M. (1991). La zona de construcción del conocimiento: trabajando por un cambio cognitivo en la educación. Ediciones Morata.

Organización de Naciones Unidas (2020). Resultados de la investigación de las denuncias de posibles violaciones de los derechos humanos a la vida, la libertad y la integridad física y moral en la República Bolivariana de Venezuela. Asamblea General de Naciones Unidas.

Ortega y Gasset, J. (1954). El hombre y la gente. Editorial Taurus.

Pérez, A. (2005). Educar para humanizar. Editorial Narcea.

Rogers, C. (1989). El proceso de convertirse en persona. Editorial Paidós.

Rogoff, B. (1993). El desarrollo cognitivo en el contexto social. Ediciones Paidós.

Sabino, C. (2004). Desarrollo y calidad de vida. Unión Editorial.

Sandoval, S. (2012). Psicología del desarrollo humano. Universidad Autónoma de Sinaloa.

Sarramona, J. (2002). Desafíos de la escuela en el siglo XXI. Editorial Octaedro.

Sartori, G. (2007). Homo videns. La sociedad teledirigida. Editorial Taurus.

Savater, F. (1997). El valor de educar. Editorial Ariel. 
Sen, A. (2000). Desarrollo y libertad. Editorial Planetas.

Tedesco, J. (2000). Educar en la sociedad del conocimiento. Fondo de Cultura Económica.

Torralba, F. (2010). Inteligencia espiritual. Plataforma Editorial.

Torres, R. (1999). Nuevo rol docente: ¿qué modelo de formación, para qué modelo educativo. Fundación Santillana.

UNESCO (2015). Orientación y Desarrollo de Capacidades sobre Educación para la Ciudadanía Mundial en América Latina y el Caribe. Reporte Informativo. Santiago de Chile.

Viola, A.; Knoll, P. y Remes, J. (2014). El índice de desarrollo humano. Boletín Universidad Nacional de San Martín, (10), pp.1-10.

Zapata, J. (2016). (Coord). Fundamentos de psicología de la salud. Pearson Educación de México.

Zimmermann, M. (2013). Pedagogía ambiental para el planeta en emergencia. Ediciones Ecoe. 